\title{
Transmission electron microscopy of cellulose. Part 1: Historical perspective.
}

\author{
Yu Ogawa*, Henri Chanzy and Jean-Luc Putaux ${ }^{\ddagger}$
}

Univ. Grenoble Alpes, CNRS, CERMAV, F-38000 Grenoble, France

* corresponding author: yu.ogawa@cermav.cnrs.fr - ORCID: 0000-0003-0677-7913

* jean-luc.putaux@cermav.cnrs.fr - ORCID: 0000-0002-9760-5369

Published in: Cellulose 26 (2019), 17-34

DOI: $10.1007 / \mathrm{s} 10570-018-2075-\mathrm{x}$ 


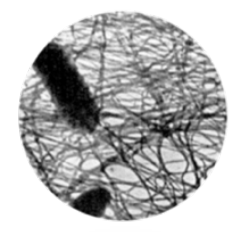

1940 s

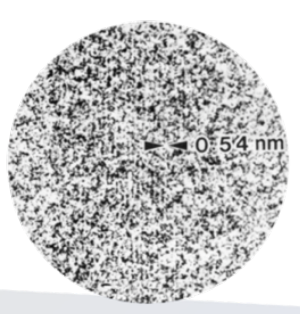

1980 s
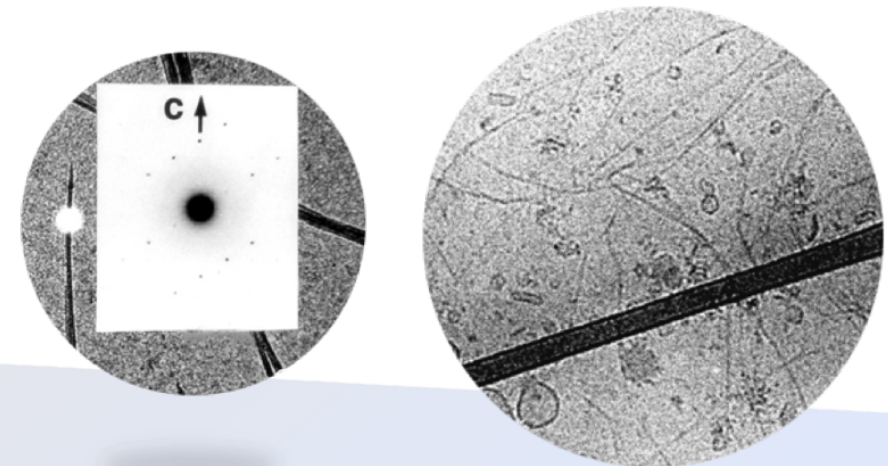

1990 s

\title{
2000 s
}

\begin{abstract}
Following the first electron micrographs of cotton in 1940, the development of transmission electron microscopy applied to native cellulose has been evolving in a series of successive advances. At first, faced with the weak contrast of the early images, the operators had to use specific electron dense contrasting agents to reveal the ultrastructure of their samples. It was thus found that all native celluloses consisted of microfibrils, with some size variations depending on the sample origin. Following this, a major advance was achieved when the electron microscopes could be adjusted with low electron doses, allowing the recording of diffraction diagrams from the electron beam-sensitive cellulose samples. Under these conditions, one could obtain information of cellulose itself and not, as before, of the contrasting agent. This important development applied to microdiffraction conditions revealed that some large cellulose microfibrils could yield spot diagrams typical of single crystals. Their recording led to a decisive progress for resolving the molecular and crystal structure of the two cellulose allomorphs, cellulose I $\alpha$ and I $\beta$. Using various combinations of diffracted beams to create the images, the so called "diffraction contrast images" could then be developed. These micrographs showed many aspects of the crystalline core of cellulose, including spectacular high-resolution images showing the molecular planes of cellulose in their crystalline environment. Today, electron diffraction, diffraction contrast imaging and low-dose electron microscopy have become major tools to follow the effect of various physical, chemical and biochemical processes at the cellulose crystalline level.
\end{abstract}

Keywords: cellulose; nanocellulose; transmission electron microscopy; electron diffraction 


\section{Introduction}

Since the dawn of mankind, cellulose-based products have played an important role for the survival of humans, providing them with shelter, fuel and clothing, which helped them to dominate the external elements and, in addition, provided them with specific tools for their daily life. More recently, cellulose serves as the base of numerous commodity products such as papers and boards as well as that of various chemicals, which are adding to the comfort of our daily life. In view of these ubiquitous products and their properties, deciphering the fine structure of cellulose has challenged the curiosity of many physicists, chemists and biologists. In this paper, we would like to present an historical perspective on the contribution of transmission electron microscopy (TEM) toward the understanding of the ultrastructure of cellulose, limiting ourselves to that of native cellulose -or cellulose I- and of a few of its fibrous allomorphic transformations.

\section{From early X-ray data to the first electron micrographs of cellulose}

Ideas about the ultrastructure of cellulose started with the use of X-ray scattering, more than one century ago. From X-ray data, it was possible not only to define the unit cell parameters of the cellulose crystal (Herzog and Jancke 1920, Sponsler 1925), but also to give average dimensions for the cellulose elements, which were deduced from the line broadening of the scattering intensities (Hengstenberg and Mark, 1928; Herzog 1929; Frey-Wyssling, 1937).

Following the development of the first commercially available transmission electron microscope by E. Ruska (Von Borries and Ruska, 1939; Ruska, 1987), cellulose scientists saw the opportunity to directly visualize the fine structure of cellulose fibers at a resolution much higher than that of the optical microscopes. Despite this potential, the first micrographs of cellulose were somewhat deceptive, lacking sufficient contrast to reveal the fine details of the fibrillar specimens, since only the thickest parts of the samples could be visualized (Ruska, 1940; Ruska and Kretschmer, 1940; Eisenhut and Kuhn, 1942, Husemann and Carnap, 1943a; Husemann and Carnap, 1943b; Ruska, 1944; Frey-Wyssling and Mühlethaler, 1946). This lack of contrast was partly due to the electron transparency of cellulose that is constituted of light atoms, but also to the use of too intense electron beams that damaged the samples (Hamann, 1942). Despite this, Franz et al. (1943) were the first to present a well-resolved image of bacterial cellulose at a 17,000 X magnification showing the intertwined cellulose microfibrillar bundles entrapping the synthesizing bacteria (Fig. 1a). 

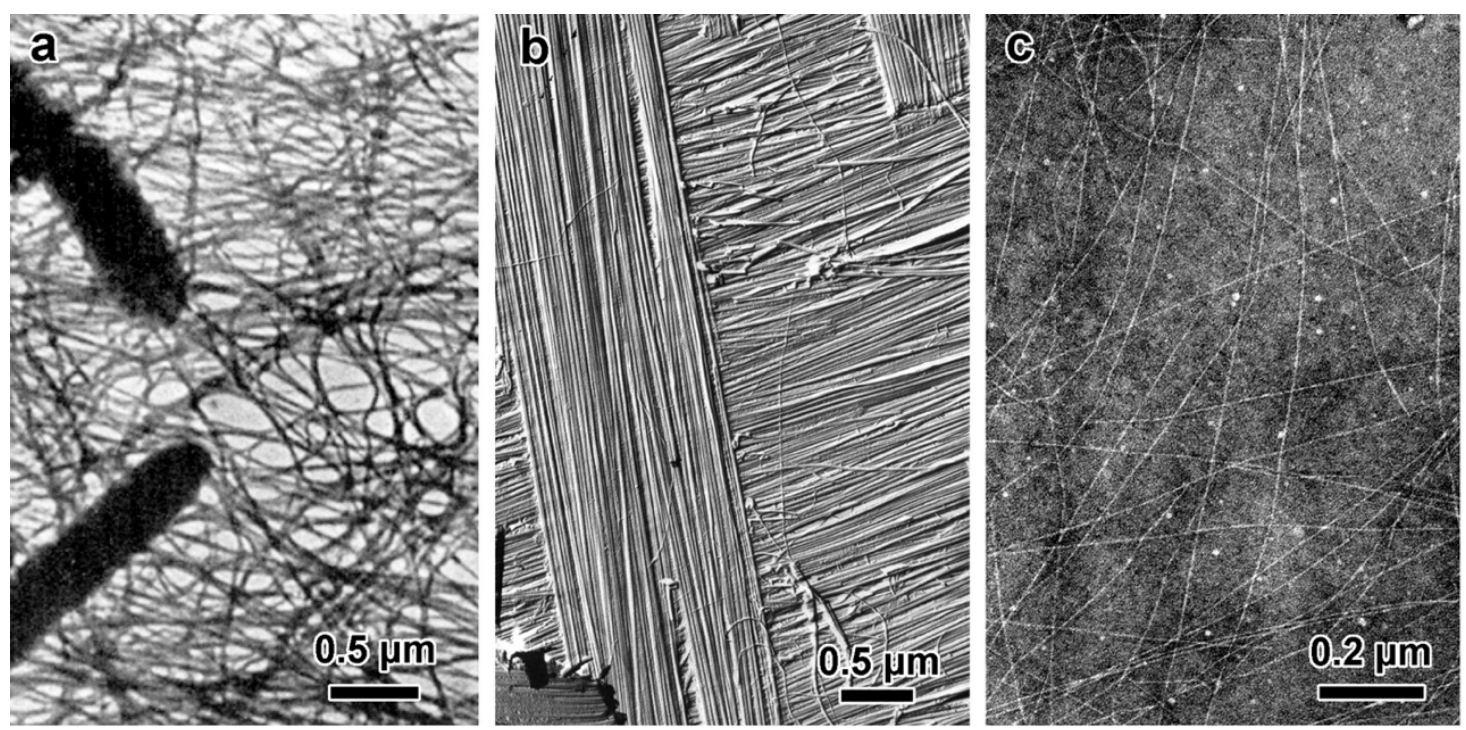

Figure 1. a) The first published image of bacterial cellulose microfibrils ${ }^{1}$ and their synthesizing bacteria. Reprinted from Franz et al. (1943), with permission from the Copyright Clearance Center. Copyright 1943, Springer. b) Freeze-etched surface with carbon platinum shadowing showing the crisscross arrays of cellulose microfibrils in a Valonia macrophysa cell wall. Reprinted from Itoh and Brown (1984), with permission from the Copyright Clearance Center. Copyright 1984, Springer. c) Image of quince slime cellulose negatively stained with phosphotungstic acid. Reprinted from Franke and Ermen (1969), with permission from De Gruyter. Copyright 1969, De Gruyter.

After these partially successful developments, contrasting methods were implemented for outlining the contours of the cellulose samples by directional heavy metal shadow-casting of the samples or of their carbon surface replicas (Fig. 1b), and staining with negative electron stains (Fig. 1c) (Kinsinger and Hock, 1948; Rånby, 1954; Heyn, 1966; Preston, 1974). In the resulting images, the information and the resolution were essentially those of the stain or of the cast and not those of cellulose itself. Nevertheless, the images were well-defined and their analysis revealed that all the investigated native celluloses samples displayed a microfibrillar texture (Frey-Wyssling et al., 1948; Kinsinger and Hock, 1948; Mühlethaler 1949; Hock, 1952; Rånby, 1954; Heyn, 1966; Itoh and Brown, 1984). These images tended to show that the cellulose microfibrils likely had diameters distributed between 20 and $40 \mathrm{~nm}$ (Hock, 1952; Mühlethaler, 1949). In some specimens, the microfibrils were particularly well-defined. This was the case for the cellulose from the cell wall of Valonia (Preston et al., 1948; Franke and Falk, 1968), from the bacterial cellulose pellicles (Mühlethaler, 1949; Rånby, 1952b), from the mantle of tunicates (Frey-Wyssling and Frey, 1950; Rånby, 1952a) and from the slime of quince and some other plants (Mühlethaler, 1950; Franke and Ermen, 1968; Husemann and Keilich, 1969).

\footnotetext{
${ }^{1}$ Throughout the text, the "microfibril "refers to the smallest fibrillar object that can be isolated from cellulosic tissues. Recently, it has often been renamed "nanofiber" or "nanofibril".
} 


\section{The fibrillated cellulose model}

With all these advances, the fibrillate structure of native cellulose became well-established (Frey-Wyssling et al., 1948; Hock, 1952) but an intense debate about the fine details of the cellulose microfibril and their relation to the constituting cellulose molecules was initiated. On the one hand, it was shown that acid hydrolysis was able to break down the microfibrils into shorter rod-like elements that had the same diameter as the parent microfibril (Husemann and Carnap, 1943a; Svedberg, 1949; Rånby and Ribi, 1950;Hock, 1950; Mukherjee and Wood, 1953; Dennis and Preston, 1961), thus indicating an alternation of crystalline and less organized parts along the microfibrils. On the other hand, a question was raised about whether the cellulose microfibrils from different origins have different diameter. At that time, it was proposed that all celluloses contained a common basic building element, namely the elementary fibril, also called the protofibril, with a cross-section dimension of $3.5 \times 3.5 \mathrm{~nm}^{2}$ (FreyWyssling and Mühlethaler, 1963; Manley, 1964; Ohad and Danon, 1964; Ohad and Mejzler, 1965; Frey-Wyssling, 1954; Frey-Wyssling et al., 1966; Heyn, 1966; Heyn, 1969; Manley, 1971). The concept of the ubiquitous elementary fibril was however challenged when narrower subfibrils were observed (Franke and Ermen, 1969; Hanna and Côté, 1974; Fengel, 1974; Herth and Meyer, 1977; Chanzy et al., 1979). Another debate was raised following a suggestion by Manley (1964) who proposed a chain-folding arrangement within the cellulose elementary fibril, with folds every $4 \mathrm{~nm}$ (Manley, 1971). This proposal, which was based on the highresolution observation of strings of beads along negatively stained specimens, could not be confirmed by other techniques. In particular Manley's model was strongly challenged when some ramie samples were cross-sectioned every $2 \mu \mathrm{m}$ and the molecular weight of the crosssectioned material could not match the expected result from a chain folding concept (Muggli et al., 1969). Another model of chain-folded cellulose elementary fibril was proposed by Bittiger et al. (1969) based on fold lengths of the order of 15 to $20 \mathrm{~nm}$, but as in the case of Manley's suggestion, this model could not be validated by other techniques.

\section{The electron diffraction contribution}

A major advance in the definition of the ultrastructure of cellulose occurred when highly crystalline samples of Valonia cellulose, acting as a cellulose model, could be analyzed by electron diffraction (Fig. 2a), using reduced electron beam intensity on never-observed specimen areas (Preston and Ripley, 1954; Balashov and Preston, 1955; Honjo and Watanabe, 1958; Bourret et al., 1972; Macchi, 1976). Following such an achievement with highly 
crystalline samples, it was soon found that less crystalline samples and essentially all celluloses could also yield electron diffraction patterns (Peterlin and Ingram, 1970; Hebert and Müller, 1974; Paralikar and Betrabet, 1977; Chanzy et al., 1978; Paralikar et al., 1979). The comparison of these patterns with those of Valonia or bacterial cellulose indicated that at least two crystalline allomorphs existed in crystalline cellulose (Hebert and Müller, 1974). Overall, the recording of these patterns required the use of low electron doses in order to minimize the electron beam damage, so that the samples could keep their crystalline structure during the recording time (Figs. 2b and 2c). It was found that the use of high voltage (Chanzy, 1975) and low temperatures (Honjo and Watanabe, 1958; Knapek, 1982) allowed for longer recording times during which the samples could be kept under diffracting conditions. Typically, for Valonia cellulose at room temperature, an accumulated dose of $200 \mathrm{e}^{-} / \mathrm{nm}^{2}$ decreased the intensity of the diffraction diagram by half at $320 \mathrm{kV}$ and this value reached $400 \mathrm{e}-/ \mathrm{nm}^{2}$ when the voltage reached $650 \mathrm{kV}$ (Chanzy 1975). On the other hand, Knapek (1982), working at $220 \mathrm{kV}$, found a ten-fold increase in the lifetime of the diffraction diagram of Valonia cellulose when decreasing the temperature of the sample to $4 \mathrm{~K}$ at $220 \mathrm{kV}$. Electron diffraction diagrams were recorded from bundles of microfibrils lying flat on the supporting TEM grids, but also on cross-sections of microfibril bundles (Fig. 3a). By using electron microdiffraction on an area as small as $40 \mathrm{~nm}$ in diameter, Revol and Goring (1983) were even able to record a diagram from the section of one single Valonia microfibril (Fig. 3b). This diagram, which consisted of three independent sharp diffraction spots, indicated that one given cellulose microfibril of Valonia was in fact a single crystal and that the directionality of the $c$ (chain) axis of the cellulose lattice could be determined from the relative position of these diffraction spots.

The parallel-chain organization in cellulose crystals was evidenced by preparing rod-like cellulose microcrystals from sulfuric acid hydrolysis of Valonia microfibrils and observing that only one of their two ends could be labelled, using a protocol devised to stain the cellulose reducing ends (Fig. 4a) (Hieta et al., 1984). This parallelism was confirmed when Valonia microfibrils were unidirectionally digested by the cellobiohydrolase CBH II from Trichoderma reesei (Cel 6A), a cellulase specific for the non-reducing ends of the cellulose molecules (Fig. 4b) (Chanzy and Henrissat, 1985). This parallel organization could be related to the biosynthetic mechanism of cellulose in Valonia cell wall, where long terminal synthesizing complexes and their attached nascent microfibrils were revealed by freeze-fracture technique (Itoh and Brown Jr., 1984). When whole cell wall fragments were sectioned, their electron diffraction diagrams showed that, in a given fragment, there was a mixture of up and down $c$ axis directions (Fig. 3c) (Revol and Goring, 1983; Sugiyama et al., 1985). Selective dark-field 
images using the $200^{2}$ diffraction spots of the up and down microfibrils revealed that the up and down directionalities were statistically distributed in a given cell wall fragment (Kim et al., 2006).
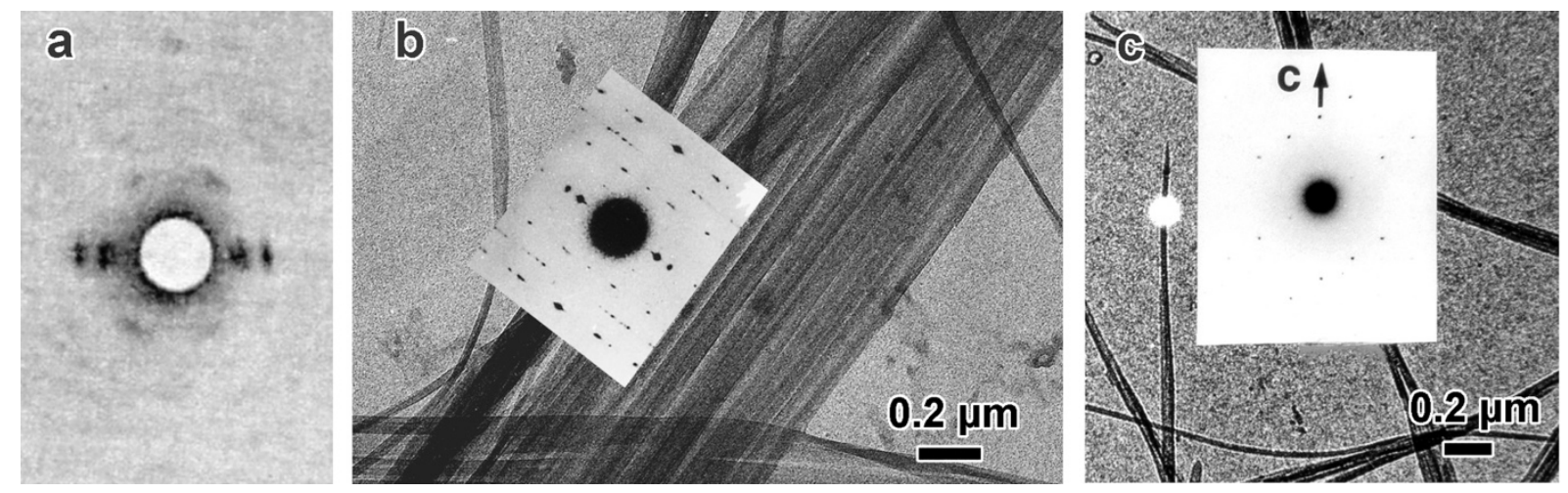

Figure 2. a) The first published electron diffraction diagram of Valonia macrophysa cellulose. Reprinted from Preston and Ripley (1954), with permission from the Copyright Clearance Center. Copyright 1954, Nature/Springer. b) Low dose image of a bundle of cellulose microfibrils from the cell wall of Microdictyon tenuis. Insert: corresponding electron fiber diagram. Reprinted from Sugiyama et al. (1991a). Copyright 1991, American Chemical Society. c) Low dose image of one nanocrystal of cellulose from Microdictyon tenuis cell wall. Insert: spot electron diffraction pattern corresponding to I $\alpha$ cellulose Reprinted from Sugiyama et al. (1991a). Copyright 1991, American Chemical Society.
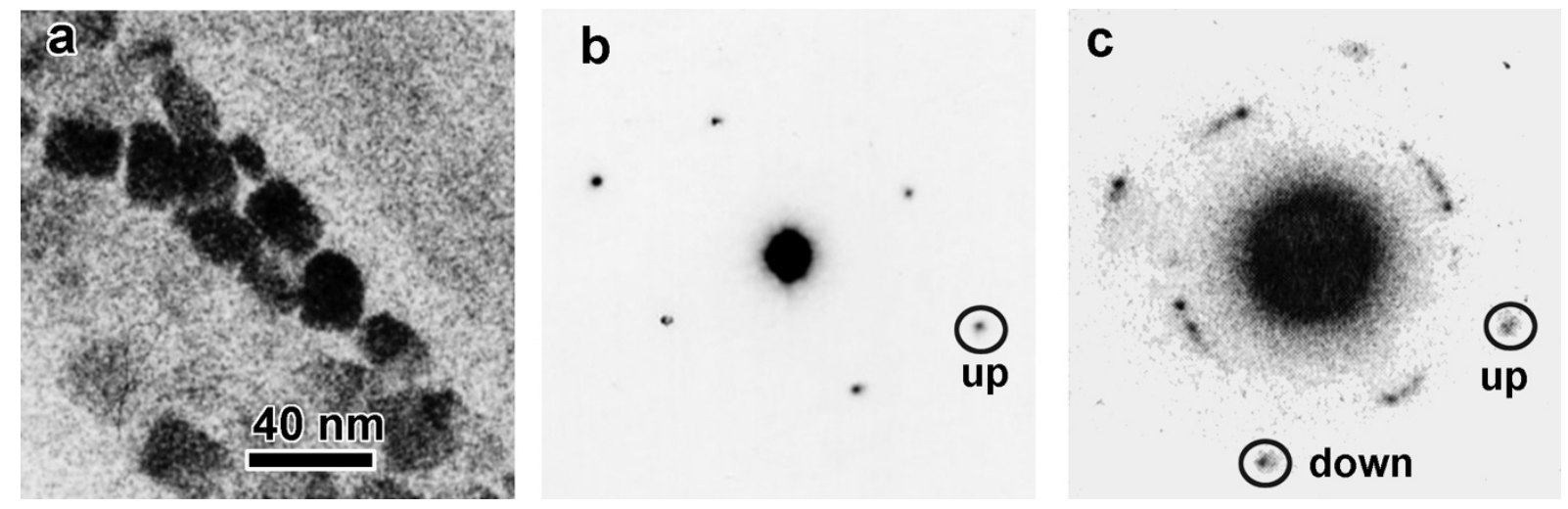

Figure 3. a) Low dose bright-field image of the cross section of a layer of cellulose microfibrils in the cell wall of one Valonia ventricosa cell showing the squarish sections of each microfibril. Reprinted from Chanzy (1990). Copyright 1990, Ellis-Horwood Ltd. b) Electron diffraction diagram of the cross-section of a single microfibril showing the "up" orientation. Reprinted with permission from from Revol and Goring (1983), with permission from the Copyright Clearance Center. Copyright 1983, Elsevier. c) Electron diffraction diagram of an area as in Fig. 3a, revealing the two orientations of "up" and "down" microfibrils in a given cluster of microfibrils. Reprinted from Chanzy (1990). Copyright 1990, Ellis-Horwood Ltd.

\footnotetext{
${ }^{2}$ Throughout the text, the crystallographic indices are referred to the $\mathrm{I}_{\beta}$ crystal structure of cellulose defined by Sugiyama et al. (1991a).
} 


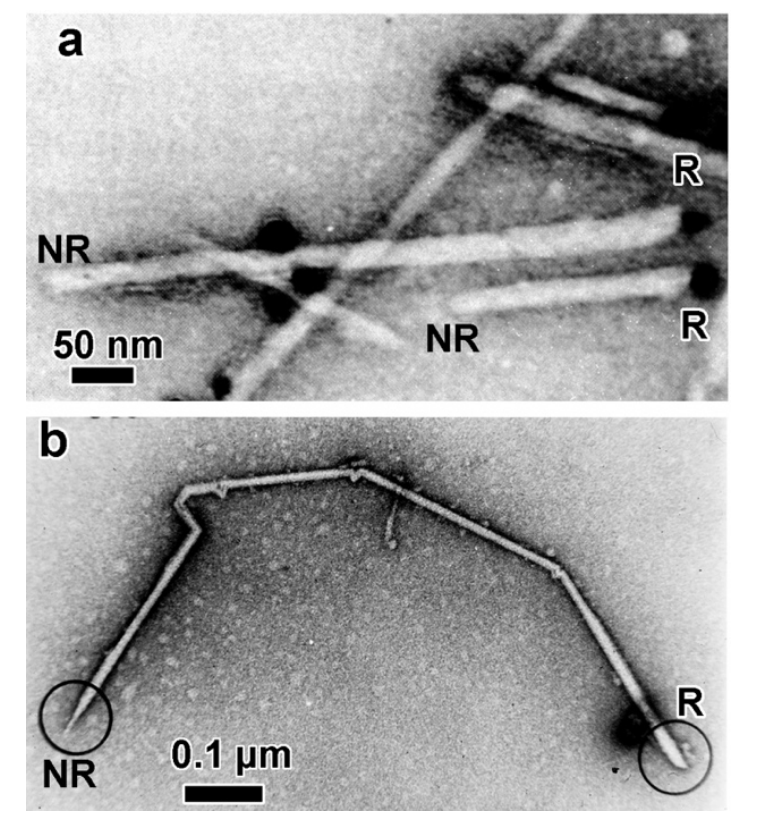

Figure 4. a) TEM image of nanocrystals from Valonia macrophysa cellulose, silver-stained exclusively at their reducing end. R: reducing end and NR: non reducing end. Reprinted from Hieta et al. (1984), with permission from the Copyright Clearance Center. Copyright 1984, Wiley. b) Image of a negatively stained nanocrystal from Valonia macrophysa cellulose showing the pointed tip at the non-reducing end after digestion with Cel6B (CHHII) from Trichoderma reesei. NR and R as in Fig. 5a. Reprinted from Chanzy and Henrissat (1985). Copyright 1985, Elsevier.

\section{Cellulose with diffraction contrast and low-dose TEM}

The routine recording of electron diffraction patterns on cellulose samples prompted the TEM users to select the diffracted beams in order to observe unstained and unshadowed specimens and to record images that were those of cellulose itself and not those of the contrasting agent. In such micrographs, a strong contrast results from the difference between the diffracting regions and those which do not diffract (Bourret et al., 1972). One could produce bright-field images by occulting all the diffracting beams with an adequate objective aperture (Figure 5a) or dark-field images (Figure 5b) by using one diffracted beam to create the image. Using interferences between the central and diffracting beams, lattice images of Valonia cellulose with a resolution of $0.54 \mathrm{~nm}$ were produced, first quite noisy (Knapek, 1982) but much better resolved later (Figure 5c) (Sugiyama et al., 1984; Sugiyama et al., 1985), using an accumulated dose of $300 \mathrm{e}-/ \mathrm{nm}^{2}$ for an image recorded at $200 \mathrm{kV}$ (Sugiyama et al., 1985). These last images, which also showed the $\left(\begin{array}{lll}2 & 0 & 0\end{array}\right)$ lattice lines of the I $\beta$ phase with a spacing of $0.39 \mathrm{~nm}$, had a crucial importance for the knowledge of the ultrastructure of cellulose since they ruled out, at least for the highly crystalline Valonia cellulose, not only the concept of chain-folded ultrastructure, but also that of the elementary fibril, since the cellulose lattice could be clearly 
seen for more than $50 \mathrm{~nm}$ along the microfibril axis and across the full $20 \mathrm{~nm}$ width of the microfibrils. Lattice images of Valonia cellulose microfibrils as well as those of other highly crystalline cellulose samples were soon produced in several laboratories. (Revol, 1985; Tsuji et al., 1985; Kuga and Brown, 1987a, 1987b; Kuga and Brown, 1989; Chanzy, 1990; Helbert et al., 1998a, 1998b).
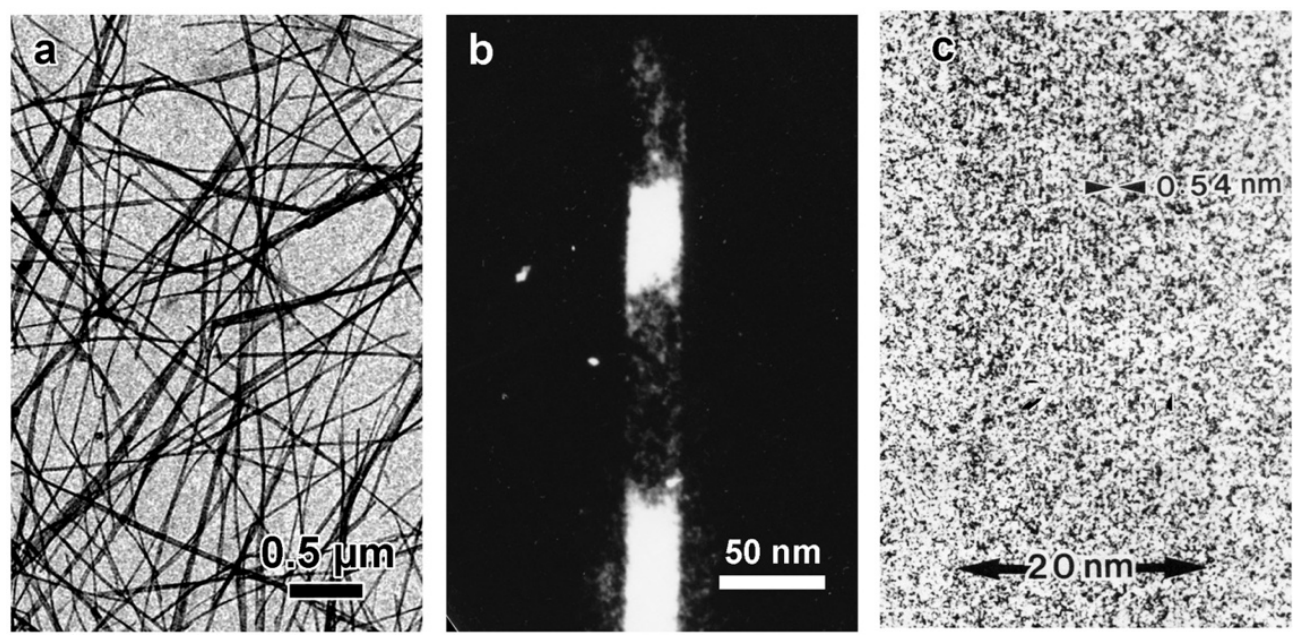

Figure 5. a) Low-dose image unstained and unshadowed of a preparation of tunicin nanocrystals. Unpublished, but taken from the collection of CERMAV micrographs. b) Dark-field image of one microfibril from Valonia macrophysa cellulose. Reprinted from Chanzy (1990). Copyright 1990, Ellis-Horwood Ltd. c) Lattice image of one microfibril from Valonia macrophysa cellulose showing the $0.54 \mathrm{~nm}$ lattice. Reprinted from Sugiyama et al. (1985), with permission from Mokuzai Gakkaishi. Copyright 1985, Mokuzai Gakkaishi.

The data from electron diffraction diagrams and from images resulting from diffraction contrast have been decisive to reveal the cross-sectional shape of some of the cellulose microfibrils (Nishiyama, 2009). For the highly crystalline cellulose from the cell wall of green algae such as Valonia and Microdictyon, bright-field images clearly showed that the microfibrils had a square section (Fig. 3a) with the (1 110$)$ and $\left(\begin{array}{lll}1 & -1 & 0\end{array}\right)$ hydrophilic planes on the sides of the squares, whereas the hydrophobic $\left(\begin{array}{lll}2 & 0 & 0\end{array}\right)$ planes were located opposite at two of the square corners (Revol, 1982; Chanzy et al., 1986; Chanzy, 1990; Sugiyama et al., 1991; Kim et al., 2006). For tunicin, the cellulose from tunicates, the microfibril sections have the shape of a parallelogram, with an acute angle of around 55 (Revol et al., 1990; Van Daele et al., 1992; Kimura and Itoh, 1996; Kimura and Itoh, 1997; Kimura and Itoh, 2004). When tunicin was converted into cellulose nanocrystals by sulfuric acid hydrolysis, the acute angle of the crystals was eroded and their section took the shape of a six-sided polygon (Helbert et al., 1998b). The microfibrils from Micrasterias cell wall presented rectangular sections defined by

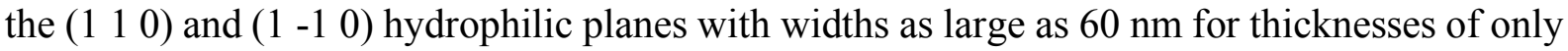


$5 \mathrm{~nm}$ (Kim et al., 1996). For microfibrils of smaller diameters, such as those of cotton, or wood, it has not been possible so far to get a clear definition of their crystalline section from diffraction contrast electron microscopy, even if a speculative model with hexagonal sections have been tentatively proposed but so far not proven (Ding and Himmel, 2006; Ding et al., 2014). Attempts to record diffraction contrast images from embedded flax fiber cross-sections showed that the individual microfibrils had a width ranging from 3 to $5 \mathrm{~nm}$ (Näslund et al., 1988), but the resolution of the images was not sufficient to get a clear picture of their contour. Taking these results together, it is likely that cellulose samples from different origins have different geometrical cross-sections and different lateral sizes, ranging from 1 or $2 \mathrm{~nm}$ to 20 and even 40 nm (Hanna and Côté, 1974; Chanzy, 1990) and that the elementary fibril concept has to be abandoned. At any rate, the cellulose microfibril can be considered as a single slender crystalline entity endowed with highly anisotropic properties (Nishiyama, 2009).

The damage created by the electron beam in cellulose induces not only a fast decrystallization of the specimens, but also a mass loss, which can be quantified by scanning TEM (STEM) measurements. Typically, for wood cellulose irradiated with a $100 \mathrm{kV}$ source, the loss of the diffraction diagram occurs at $130 \mathrm{e}-/ \mathrm{nm}^{2}$, but at this irradiation level, there is a negligible mass loss. Following increasing irradiation dose, the mass loss of cellulose increases rapidly since $68 \%$ of the initial mass of Valonia has disappeared after an irradiation dose of $3 \times 10^{5} \mathrm{e}^{-} / \mathrm{nm}^{2}$ (Mary et al., 1986). During this mass loss, the cellulose molecules are partially broken into small volatile fragments that are sucked up by the TEM vacuum pumps. This mass loss explains why the contrast of cellulose samples is so drastically reduced in the images of unstained or unshadowed cellulose samples if low electron beam dose conditions are not applied.

\section{Cellulose allomorphs seen by TEM}

By diffraction contrast imaging, it was possible to follow the allomorphic transitions of Valonia cellulose subjected to specific chemical reagents, which kept the fibrous nature of the original sample. When immersed into ethylenediamine, followed by washing in methanol, the samples became converted into the cellulose III $_{I}$ allomorph. This transition, which could be visualized by bright and dark-field (Roche and Chanzy, 1981; Chanzy et al., 1986) or lattice imaging (Sugiyama et al., 1987) showed how the large initial crystals of Valonia were broken into much smaller ones, which thus became accessible to further chemical transformation. Similarly, in the partial fibrous transformation of Valonia cellulose I into cellulose II, the occurrence of lamellar crystals of cellulose II could also be observed by dark-field imaging. 
These cellulose II crystals were hooked perpendicular to the remaining microfibrillar cellulose I core in a "shish-kebab" type morphology (Chanzy and Roche, 1976). This revealed that the cellulose microfibril surface could promote the nucleation of cellulose II, when crystallizing from dilute cellulose solutions (Buléon et al. ,1976).

The mastering of the electron microdiffraction technique was decisive to unravel the crystallography of cellulose, which had been debated for a long time (Honjo and Watanabe, 1958; Helbert and Müller, 1974). By using a specific alkaline hydrothermal treatment, Sugiyama et al. (1990) were able to deconvolute the Valonia cellulose fiber diagram as a superposition of two diagrams. One of them resulted from monoclinic crystalline domains, whose unit cell could be totally indexed along a two-chain $P 2{ }_{1}$ structure. The other part came from triclinic crystalline domains, whose unit cell could not be resolved. When individual microcrystals resulting from the acid hydrolysis of Microdictyon cellulose were analyzed by a beam as small as 20-100 $\mathrm{nm}$ in diameter, two families of spot diagrams were recorded, when moving along a given microcrystal. In one family, referred to as I $\alpha$, the rows of the diffraction spots were inclined with respect to the long dimension of the crystal (Fig. 2c), while in the second family, referred to as $\mathrm{I} \beta$, they were organized in a perpendicular fashion. The recording of full diffraction datasets of these two families allowed identifying the two allomorphs and yielding their unit cell parameters and symmetry elements. Cellulose I $\alpha$ consisted of a one-chain $P 1$ cell, and in cellulose $\mathrm{I} \beta$ the $P 2_{1}$ symmetry and two parallel chains located on the symmetry axes were confirmed (Sugiyama et al., 1991a). This finding was able not only to lift all ambiguities about the unit cell determination of the cellulose crystal, but also to reconcile the crystallography of cellulose with data resulting from ${ }^{13} \mathrm{C} \mathrm{CP} / \mathrm{MAS}$ NMR (Atalla and VanderHart, 1994) or FTIR spectroscopy (Sugiyama et al., 1991b). Using dark-field imaging with diffraction spots attributed to cellulose I $\alpha$ allowed imaging such domains in Microdictyon and Cladophora cellulose (Sugiyama et al. 1991a; Imai et al., 2003). Nanodomains of cellulose I $\alpha$ and I $\beta$ were also deduced from a careful analysis of the electron microdiffraction patterns of a series of cellulose microfibrils from the cell wall of green marine algae (Imai and Sugiyama, 1998).

\section{TEM contribution to cellulose biochemistry}

The data resulting from electron diffraction experiments have helped in deciphering several important features of biosynthesis or the biodegradation of cellulose. In a combination of direct staining of the reducing ends of cellulose chains and micro-diffraction/tilting electron crystallography, Koyama et al. (1997) proved that the polymerization of cellulose takes place 
at the non-reducing end of the growing cellulose chain. By electron crystallography applied to the I $\alpha$ phase of Valonia cellulose, it was also shown that during biosynthesis, the microfibrils were laid flat and without twisting, with their $a^{*}$ reciprocal axis perpendicular to the plane of the plasma membrane (Sugiyama et al., 1994). This result well complemented the images of freeze-etched specimens published earlier showing the nascent Valonia microfibrils, still hooked to their synthesizing terminal complexes, sliding at the plasma membrane surface (Itoh and Brown Jr. ,1984).

More recently, the addition of uridine diphosphate (UDP) to suspensions of microsomal fractions of blackberry cultured cells induced the rapid in vitro synthesis of cellulose microfibrils, which could be observed by cryo-TEM after quench-freezing into liquid ethane and introduction at low temperature into the electron microscope (Fig. 6). The resulting microfibrils, observed in bright-field mode, were remarkably insensitive to the acid Updegraff reagent and, when probed by electron diffraction, revealed a crystallinity substantially higher than that of their in vivo counterpart (Lai-Kee-Him et al. 2002).

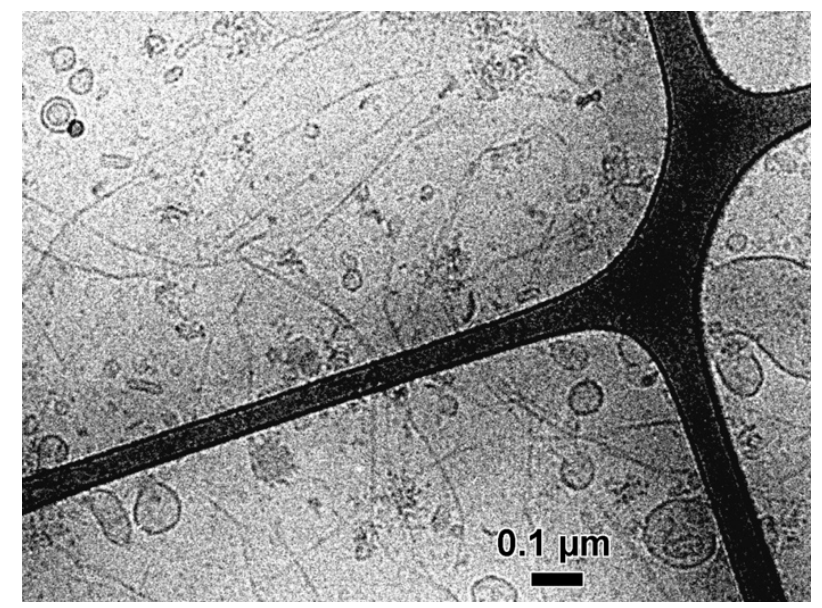

Figure 6. Cryo-TEM image of a taurocholate extract of a Rubus fructicosus microsomal fraction after incubation with UDP-glucose, leading to the in vitro production of cellulose microfibrils. Reprinted from Lai-Kee-Him et al. (2002). Copyright 2002, American Society for Biochemistry and Molecular Biology.

Regarding the biodegradation of cellulose, an elegant study combining specific staining with microdiffraction/tilting demonstrated that the hydrophobic cellulase binding module (CBM) did not adsorb on the hydrophilic $\left(\begin{array}{lll}1 & 1 & 0\end{array}\right)$ and $\left(\begin{array}{lll}1 & -1 & 0\end{array}\right)$ faces of Valonia microcrystals, but at the hydrophobic (2 00 ) planes located at two of the corners (Lehtiö et al., 2003).

\section{Conclusions}


After the first attempts to record electron micrographs of cellulose close to 80 years ago, TEM has been slowly developing as a major tool for the definition of the ultrastructure of cellulose, providing meaningful local structural details, while the commonly used scattering and spectroscopic techniques were only able to yield average structural information. In the evolving electron microscopy of cellulose, a decisive milestone was reached in the 1950s, when it was realized that cellulose was degraded by intense electron beams and thus, it was only when low doses were used that cellulose could be preserved in the electron microscope. By using minimum electron dose conditions, it became possible to record electron diffraction diagrams together with diffraction contrast or low-dose images, where the chemical integrity of the samples was essentially maintained. Under such conditions, major advances were made to decipher the crystallography of cellulose, the ultrastructure of its crystalline domains and to follow important chemical or biochemical processes at the cellulose crystal level.

During the period covered by this review, TEM images were essentially recorded on photographic emulsion specially designed for electron beams. This situation no longer exists, as photographic films for electron microscopy are being phased out and replaced by digital cameras which equip all new microscopes. This development opens new avenues for the recording of micrographs with very low electron doses, leading to images with a better resolution, likely showing unsuspected details. With this advance, a new chapter in the transmission electron microscopy of cellulose is just opening.

\section{References}

Atalla RH, Vander Hart DL (1984) Native cellulose: a composite of two distinct crystalline forms. Science 223:283-285

Balashov V, Preston RD (1955) Fine structure of cellulose and other microfibrillar substances. Nature 176:64-65

Bittiger H, Husemann E, Kuppel A (1969) Electron microscope investigations of fibril formation. J Polym Sci Part C 28:45-56

Bourret A, Chanzy H, Lazaro R (1972) Crystallite features of Valonia cellulose by electron diffraction and dark field microscopy. Biopolymers 11: 893-898

Buléon A, Chanzy H, Roche E (1976) Shish kebab-like structure of cellulose. Polym Lett $15: 265-270$

Chanzy H (1990) Aspects of cellulose structure. In: Cellulose Sources and Exploitation. Industrial Utilization, Biotechnology and Physico-chemical Properties. JF Kennedy, GO Phillips and PA Williams edits. Ellis Horwood Ltd, Chichester, pp 3-12

Chanzy H, Henrissat B (1985) Unidirectional degradation of Valonia cellulose microcrystals. FEBS Lett 184:285-288 
Chanzy H, Henrissat B, Vuong, R (1986) Structural changes of cellulose crystals during the reversible transformation Cellulose $\mathrm{I} \rightleftarrows \mathrm{III}_{\mathrm{I}}$ in Valonia. Holzforschung 40:25-30

Chanzy H, Imada K, Mollard A, Vuong R, Barnoud F (1979) Crystallographic aspects of subelementary fibrils occurring in the wall of the rose cells cultures in vitro. Protoplasma 100:303-316

Chanzy H, Imada K, Vuong R (1978) Electron diffraction from the primary wall of cotton fibers. Protoplasma 94:299-306

Chanzy HD (1975) Irradiation de la cellulose de Valonia au microscope à 1 MV. Bulletin BIST, CEA 207:55-57

Chanzy HD, Roche EJ (1976) Fibrous transformation of Valonia cellulose I into cellulose II. Appl Polym Symp 28:701-711

Dennis DT, Preston RD (1961) Constitution of cellulose microfibrils. Nature 191:667-668

Ding S-H, Zhao S, Zeng Y (2014) Size, shape, and arrangement of native cellulose fibrils in maize cell walls. Cellulose 21:863-871

Ding S-Y, Himmel ME (2006) The maize primary cell wall microfibrils: a new model derived from direct visualization. J Agr Food Chem 54:597-606

Eisenhut O, Kuhn E (1942) Lichtmikroskopische und übermikroskopische Untersuchungen an natürlichen und künstlichen Cellulosefasern. Angew Chem 55:198-206

Fengel D (1974) 10-Å-Fibrillen in Cellulose. Naturwiss 61:31-32

Franke WW, Ermen B (1969) Negative staining of plant slime cellulose: an examination of the elementary fibril concept. Z. Natusforsh 24b:918-922

Franke WW, Falk H (1968) Enzymatisch isolierte Cellulose-Fibrillen der Valonia-Zellwand. Z Naturforsch 23b:272-274

Franz E, Schiebold E, Weygand C (1943) Über den morphologischen Aufbau der Bakterienzellulose. Natuswissenschaften 31:350

Frey-Wyssling A (1937) Über die röntgenmetrische Vermessung der submikrosskopischen Räume in Gerüstubstanzen. Protoplasma 27:372-411

Frey-Wyssling A, Frey R (1950) Tunicin im Elektronmikroscop. Protoplasma 39:656-660

Frey-Wyssling A, Mühlethaler K (1946) Submicroscopic structure of cellulose. J Polym Sci $1: 172-174$

Frey-Wyssling A, Mühlethaler K (1963) Die Elementarfibrillen der Cellulose. Makromol Chemie 62: 25-30

Frey-Wyssling A, Mühlethaler K, Muggli R (1966) Elementarfibrillen als Grundbausteine der nativen Cellulose. Holz als Roh-und Werkstoff 24:443-444

Frey-Wyssling A, Mühlethaler K, Wyckoff RWG (1948) Mikrofibrillenbau der Pflanzlichen Zellwände. Experientia 4:475-476

Frey-Wyssling A. (1954) The fine structure of cellulose microfibrils. Science 119:80-82

Hamann A (1942) Das Vehalten von Zellulosefäsern im Elektronmikroskop. Kolloid-Z 100: $248-254$

Hanna B, Côté WAJ (1974) The sub-elementary fibril of plant cell wall cellulose. Cytobiologie 10:102-116

Hebert JJ, Müller LL (1974) An electron diffraction study of the crystal structure of native cellulose. J Appl Polym Sci 18:3373-3377

Helbert W, Nishiyama Y, Okano T, Sugiyama J (1998b) Molecular imaging of Halocynthia papillosa. J Struct Biol 124:42-50 
Helbert W, Sugiyama J, Kimura S, Itoh T (1998a) High-resolution electron microscopy on ultrathin sections of cellulose microfibrils generated by glomerulocytes in Polyzoa vesiculiphora. Protoplasma 203:84-90

Hengstenberg J, Mark H (1928) Über Form und Grösse der Mizelle von Zellulose und Kautschuk. Z Kristallographie 69:271-284

Herth W, Meyer Y (1977) Ultrastructural and chemical analysis of the wall fibrils synthesized by tobacco mesophyll protoplast. Biol Cell 30:33-40

Herzog RO (1929) Zur Chemie und Physik der Kunsteide. Z Angew Chemie 41:531-536

Herzog RO, Jancke W (1920) Röntgenspektrographische Beobachtungen an Zellulose. Z Physik 3:196-198

Heyn ANJ (1966) The microcrystalline structure of cellulose in cell walls of cotton, ramie, and jute fibers as revealed by negative staining of sections. J Cell Biology 29:181-187

Heyn ANJ (1969) The elementary fibril and supermolecular structure of cellulose in soft wood fibre. J Ultrastruct Res 26:52-68

Hieta K, Kuga S, Usuda M (1984) Electron staining of reducing ends evidences a parallelchain structure in Valonia cellulose. Biopolymers 23:1807-1810

Hock CW (1950) Degradation of cellulose as revealed microscopically. Text Res J 20:141-151

Hock, CW (1952) The fibrillate structure of natural cellulose. J Polym Sci 8:425-434

Honjo G,Watanabe M (1958) Examination of cellulose fibre by the low-temperature specimen method of electron diffraction and electron microscopy. Nature 181:326-328

Husemann E, Carnap A (1943a) Übermikroskopische Untersuchungen an hydrolytisch abgebauten Fasern. J Makromol Chemie 1:16-27

Husemann E, Carnap, A (1943b) Übermikroskopische Untersuchungen an gemahlenen Cellulosefasern. Miteilung über makromolekulare Verbindungen. J Makromol Chem $1: 158-167$

Husemann E, Keilich, G (1969) Charakterisierung der Cellulose aus Quittenkernen. Cellulose Chem Technol 3:445-453

Imai T, Putaux J-L, Sugiyama J (2003) Geometric phase analysis of lattice images from algal cellulose. Polymer 44:1871-1879

Imai T, Sugiyama $\mathrm{J}$ (1998) Nanodomains of $\mathrm{I}_{\alpha}$ and $\mathrm{I}_{\beta}$ cellulose in algal microfibrils. Macromolecules 31:6275-6279

Itoh T, Brown RM Jr (1984) The assembly of cellulose microfibrils in Valonia macrophysa Kütz. Planta 160:372-381

Kim N-H, Herth W, Vuong R, Chanzy H (1996) The cellulose system in the cell wall of Micrasterias. J Struct Biol 117:195-203

Kim N-H, Imai T, Wada M, Sugiyama J (2006) Molecular directionality in cellulose polymorphs. Biomacromolecules 7:274-280

Kimura S, Itoh T (1996) New cellulose synthesizing complexes (terminal complexes) involved in animal cellulose biosynthesis in the tunicate Metandrocarpa uedai. Protoplasma 194:151-163

Kimura S, Itoh T (1997) Cellulose network of hemocoel in selected compound styleid ascidians. J Electron Microsc 46:327-335

Kimura S, Itoh T (2004) Cellulose synthesizing terminal complexes in the ascidians. Cellulose 11:377-383 
Kinsinger WG, Hock CW (1948) Electron microscopical studies of natural cellulose fibers. Ind Eng Chem 40:1711-1716

Knapek E (1982) Properties of organic specimens and their support at $4 \mathrm{~K}$ under irradiation in an electron microscope. Ultramicoscopy 10:71-86

Koyama M, Helbert W, Imai T, Sugiyama J, Henrissat B (1997) Parallel-up structure evidences the molecular directionality during biosynthesis of bacterial cellulose. Proc Natl Acad Sci USA 94:9091-9095

Kuga S, Brown RM Jr (1987a) Lattice imaging of ramie cellulose. Polym Commun 28:311-314

Kuga S, Brown RM Jr (1987b) Practical aspects of lattice imaging of cellulose. J Electr Microsc Technique 6:349-356

Kuga S, Brown RM Jr (1989) Correlation between structure and the biogenic mechanisms of cellulose; new insights based on recent electron microscopic findings. In: Cellulose and Wood Chemistry and Technology. Ed. C. S. Schuerch. John Wiley and Sons Inc., New York pp. 677-688

Lai-Kee-Him J, Chanzy H, Müller M, Putaux J-L, Imai T, Bulone V (2002) In vitro versus in vivo cellulose microfibrils from plant primary wall synthases: structural differences. $\mathrm{J}$ Biol Chem 277:36931-36939

Lehtiö J, Sugiyama J, Gustavsson M, Fransson L, Linder M, Teeri T (2003) The binding specificity and -affinity determinant of family 1 and family 3 cellulose binding modules. Proc Natl Acad Sci USA 100: 484-489

Macchi EM (1976) Supermolecular structure for cellulose I. An electron diffraction study on Valonia fibers. Appl Polym Symp 28:763-776

Manley R St John (1971) Molecular morphology of cellulose. J Polym Sci A2 9:1025-1059

Manley R St John (1964) Fine structure of native cellulose microfibrils. Nature 204:1155-1157

Mary M, Revol J-F, Goring DAI (1986) Mass loss of wood and its components during transmission electron microscopy. J Appl Polym Sci 31:957-963

Muggli R, Elias H-G, Mühlethaler K (1969) Zum Feinbau der Elementarfibrillen der Cellulose. Die Makromol Chemie 121:290-294.

Mühlethaler K (1949) Electron micrographs of plant fibers. Biochim Biophys Acta 3:15-25.

Mühlethaler K (1950) The structure of plant slimes. Exp Cell Res 1:341-350

Mukherjee SM, Woods HJ (1953) X-ray and electron microscope studies of the degradation of cellulose by sulphuric acid. Biochim Biophys Acta 10:499-511.

Näslund P, Vuong R, Chanzy H, Jésior J-C (1988) Diffraction contrast transmission electron microscopy on flax fiber ultrathin cross sections. Text Res J 58:414-417

Nishiyama J (2009) Structure and properties of the cellulose microfibril. J Wood Sci 55:241-249

Ohad I, Danon D (1964) On the dimensions of cellulose microfibrils. J Cell Biol 22:302-305

Ohad I, Mejzler D (1965) On the ultrastructure of cellulose microfibrils. J Polym Sci A 3:399-406

Paralikar KM, Betrabet SM (1977) Electron diffraction technique for the determination of cellulose crystallinity. J Appl Polym Sci 21:899-903.

Paralikar KM, Betrabet SM, Bhat NV (1979) The crystal structure of cotton cellulose investigated by an electron diffraction technique. J Appl Cryst 12:589-591

Peterlin A, Ingram P (1970) Morphology of secondary wall fibrils in cotton. Text Res J 40:345-354 
Preston RD (1974) The Physical Biology of Plant Cell Walls. London Chapman and Hall Ltd. London,

Preston RD, Nicolai E, Reed R, Millard A (1948) An electron microscope study of cellulose in the wall of Valonia ventricosa. Nature 162:665-667

Preston RD, Ripley GW (1954) Electron diffraction diagrams of cellulose microfibrils in Valonia. Nature 174:76-77

Rånby B (1952a) Physico-chemical investigations on animal cellulose (Tunicin). Arkiv for Kemi 4:241-248

Rånby B (1952b) Physico-chemical investigations on bacterial cellulose. Arkiv for Kemi $4: 249-255$

Rånby B, Ribi E (1950) Über den Feinbau der Zellulose. Experientia 6:12-14

Rånby BG (1954) Über die Feinstruktur der nativen Cellulosefasern. Makromol. Chemie $13: 40-52$

Revol J-F (1982) On the cross-sectional shape of cellulose crystallites in Valonia ventricosa. Carbohydr Polym 2:123-124

Revol J-F (1985) Change of the $d$-spacing in cellulose crystals during lattice imaging. J Mat Sci Lett 4:1347-1349.

Revol J-F, Goring DAI (1983) Directionality of the fibre $c$-axis of cellulose crystallites in microfibrils of Valonia ventricosa. Polymer 24:1547-1550

Revol J-F, Van Daele Y, Gaill F (1990) On the cross sectional shape of cellulose crystallites in the tunicate Halocynthia papillosa. Proceedings of the XII ${ }^{\text {th }}$ International Congress of Electron Microscopy. San Francisco Press Inc. p. 566

Roche E, Chanzy H (1981) Electron microscopy study of the transformation of cellulose I

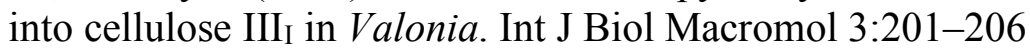

Ruska E (1944) Zur Enwicklung der Übermikroskopie und über ihre Beziehungen zur Kolloidsforschung. Kolloid-Z 107:2-16

Ruska E (1987) The development of electron microscope and of electron microscopy. Rev Modern Phys 59:627-638

Ruska H (1940) Über Strukturen von Zellulosefasern. Kolloid-Z 92:276-285

Ruska H, Kretschmer M (1940) Übermikroskopische Untersuchungen den Abbau von Zellulosefasern. Kolloid-Z 93:163-166

Sponsler OL (1925) X-ray diffraction patterns from plant fibers. J Gen Physiol 9:221-233

Sugiyama J, Chanzy H, Revol J-F (1994) On the polarity in the cell wall of Valonia. Planta 193:260-265

Sugiyama J, Harada H, Fujiyoshi Y, Uyeda N (1985) Lattice image from ultrathin sections of cellulose microfibrils in the cell wall of Valonia macrophysa Kütz. Planta 166:161-168.

Sugiyama J, Harada H, Fujiyoshi Y, Uyeda N (1985) Observation of cellulose microfibrils in Valonia macrophysa by high resolution electron microscopy. Mokuzai Gakkaishi 31:61-67.

Sugiyama J, Harada H, Saiki H (1987) Crystalline morphology of Valonia macrophysa

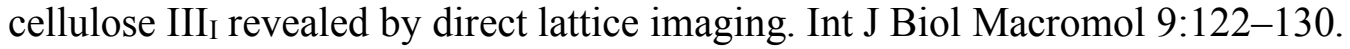

Sugiyama J, Okano T, Yamamoto H, Horii F (1990) Transformation of Valonia cellulose crystals by an alkaline hydrothermal treatment. Macromolecules 23:3196-3198

Sugiyama J, Persson J, Chanzy H (1991b) Combined infrared and electron diffraction study of the polymorphism of native cellulose. Macromolecules 24:2451-2466 
Sugiyama J, Vuong R, Chanzy H (1991a) Electron diffraction study on the two crystalline phases occurring in native cellulose from an algal cell wall. Macromolecules 24:4168-4175

Svedberg T (1949) Cellulosans struktur och polymolekylarite. Svensk Papperstidning 7:157-164.

Tsuji M, Roy SK, Manley RSt John (1985) Lattice imaging of radiation-sensitive polymer crystals. J Polym Sci Polym Phys Ed 23:1127-1137

Van Daele Y, Revol J-F, Gaill F, Goffinet G (1992) Characterization and supramolecular architecture of the cellulose-protein fibrils in the tunic of the sea peach (Halocynthia papillosa, Ascidiacea, Urochordata). Biol Cell 76:87-96

von Borries B, Ruska E (1939) Ein Übermikroskop für Forschungsinstitute. Naturwiss $27: 577-582$ 